\title{
PERAN MAINTENANCE DALAM MEMODERASI PENGARUH SCHEDULING TERHADAP KINERJA MASKAPAI PENERBANGAN (Studi Pada Garuda Indonesia Airline)
}

\author{
Tri Satya Pradnyandari ${ }^{1}$ \\ Ni Ketut Purnawati ${ }^{2}$ \\ ${ }^{\mathbf{1}, \mathbf{Z}}$ Fakultas Ekonomi dan Bisnis Universitas Udayana, Bali, Indonesia \\ e-mail: trisatya26@gmail.com ${ }^{1}$
}

\begin{abstract}
ABSTRAK
Sektor jasa telah berkontribusi pada sektor ekonomi salah satunya dalam peningkatan mobilitas masyarakat melalui jasa transportasi udara. Pemanfaatan sektor jasa ini cenderung meningkat setiap tahunnya, setiap maskapai berupaya untuk memberikan keselamatan, kepuasan pelanggan, serta kinerja ketepatan waktu (On Time Performance/OTP). OTP merupakan persentase nilai perbandingan actual time dengan scheduled time ketika kegiatan penerbangan dilakukan. Gap besar mengindikasikan adanya cancel/delay yang disebabkan oleh berbagai faktor seperti kurangnya waktu dalam persiapan preflight, penanganan pesawat, crewing, maupun faktor lainnya. Kurangnya waktu persiapan preflight dapat diakibatkan oleh banyaknya jadwal penerbangan ataupun plotting time untuk aktivitas yang kurang optimal (scheduling). Penanganan pesawat yang cukup lama salah satunya dapat diakibatkan oleh ketidakmampuan maskapai dalam mengoptomalkan maintenance yaitu ketidakmampuan dalam menemukan permasalahan dengan cepat (corrective maintenance yang kurang optimal) ataupun dapat disebabkan oleh lamanya persiapan akibat ketidakoptimalan preventive maintenance. Penelitian ini menggunakan metode penentuan sampel yaitu simple random sampling dengan total sampel sejumlah 92 orang crew/staf. Pengumpulan data yang digunakan yaitu metode observasi, wawancara, serta kuesioner dengan teknik analisis data yaitu Moderated Regression Analysis (MRA). Penelitian menghasilkan adanya pengaruh positif scheduling terhadap kinerja OTP yang kemudian mampu dimoderasi maintenance.
\end{abstract}

Kata Kunci: scheduling, on time performance, maintenance.

\begin{abstract}
The service sector's contributed to the economic sector as increasing the mobility of the people through air transportation services. Each airline strives to provide safety, customer satisfaction, and On Time Performance (OTP) because of the utilization tends to increase every year. OTP is the comparisons percentage value of actual time with scheduled time when flight activities are carried out. Large gaps indicate cancel/delay which can be caused by various factors such as lack of time in preflight preparation, aircraft handling, crewing, and others. The lack of preflight preparation time caused by nonoptimal scheduling ( many flight schedules or inefficiencies plotting time on activity). The delayed time on handling aircraft one of which caused by the inability of airline to optimize maintenance activity such as inability to find problems quickly (corrective maintenance that is less than optimal) or the length of preparation due to preventive maintenance. The method of determining sample in this study's simple random sampling with total sample of $92 \mathrm{crew} /$ staff. Data collection is done by observation, interviews, and questionnaires with data analysis technique namely Moderated Regression Analysis (MRA). The result can concluded, scheduling has a positive effect on OTP which was then able to be moderated by maintenance.
\end{abstract}

Keywords: scheduling, on time performance, maintenance. 
Tri Satya Pradnyandari, Peran Maintenance Dalam...

\section{PENDAHULUAN}

Sektor jasa merupakan salah satu sektor yang berhasil berkontribusi terhadap sektor ekonomi seperti penyediaan lapangan pekerjaan, pemenuhan kebutuhan masyarakat secara ekonomis, serta pemenuhan kebutuhan masyarakat secara sosial yaitu melalui peningkatan mobilitas masyarakat (Heizer dan Render, 2015; Sutandi, 2015). Sektor jasa yang memberikan pelayanan jasa berupa mobilitas kepada masyarakat adalah jasa transportasi. Transportasi merupakan jasa yang hingga kini mendapat banyak perhatian dari masyarakat oleh karena kebutuhan masyarakat untuk berinteraksi, bekerja, ataupun melakukan aktivitas lainnya. Kebutuhan untuk menjangkau berbagai tempat yang melampaui batasbatas wilayah dengan cepat menyebabkan adanya peningkatan pemanfaatan jasa transportasi khususnya transportasi udara.

Peningkatan pemanfaatan jasa ditunjukkan dengan adanya kenaikan jumlah penumpang dari tahun ke tahun dengan jumlah per tahun dari salah satu bandar udara tersibuk mencapai dua puluh juta penumpang hanya untuk penerbangan domestik. Pemanfaatan tersebut ditunjukkan pada Tabel 1 berikut.

Tabel 1.

Jumlah Penumpang Penerbangan Domestik di Bandar Udara Utama Indonesia Periode 2013-2018 (dalam Orang)

\begin{tabular}{|c|c|c|c|c|c|c|}
\hline $\begin{array}{l}\text { Bandar } \\
\text { Udara }\end{array}$ & $\begin{array}{c}2013 \\
\text { TW 1-4 }\end{array}$ & $\begin{array}{c}2014 \\
\text { TW 1-4 }\end{array}$ & $\begin{array}{c}2015 \\
\text { TW 1-4 }\end{array}$ & $\begin{array}{c}2016 \\
\text { TW 1-4 }\end{array}$ & $\begin{array}{c}2017 \\
\text { TW 1-4 }\end{array}$ & $\begin{array}{c}2018 \\
\text { TW 1-2 }\end{array}$ \\
\hline Polonia & 3.174 .224 & 3.134 .138 & 3.226 .695 & 3.648 .253 & 3.677 .723 & 2.591 .809 \\
\hline $\begin{array}{c}\text { Soekarno } \\
\text { Hatta }\end{array}$ & 20.659 .308 & 20.265 .692 & 19.131 .400 & 20.575 .982 & 21.931 .280 & 15.161 .612 \\
\hline Juanda & 7.264 .393 & 6.987 .700 & 6.857 .696 & 8.019 .635 & 7.924 .393 & 5.495 .402 \\
\hline $\begin{array}{c}\text { I Gusti } \\
\text { Ngurah Rai }\end{array}$ & 4.244 .311 & 4.516 .163 & 4.122 .180 & 4.925 .589 & 5.128 .687 & 3.714 .920 \\
\hline Hasanudin & 3.470 .472 & 3.147 .580 & 3.306 .353 & 3.925 .151 & 4.118 .039 & 2.882 .522 \\
\hline
\end{tabular}


Peningkatan pemanfaatan ini menyebabkan adanya peluang dengan pasar yang cukup tinggi sehingga memungkinkan para pebisnis untuk masuk pada bisnis jasa penerbangan. Para pebisnis berupaya untuk memenangkan persaingan melalui keunggulan kompetitif yang dimiliki masing-masing pebisnis yang mana keunggulan kompetitif tersebut haruslah mampu menciptkan added value yang dapat menggambarkan kinerja dari perusahaan. Dalam jasa transportasi, khususnya transportasi udara, ukuran kinerja perusahaan yaitu maskapai dapat dilihat dari tiga hal yaitu (1) keselamatan, (2) On Time Performance (OTP), serta (3) pelayanan kepada konsumen.

Keselamatan merupakan hal terutama dari bisnis jasa ini sehingga tingkat kinerja keselamatan maskapai dapat dilihat dari sedikitnya jumlah kecelakaan penerbangan yang terjadi, berat atau ringannya jenis kecelakaan yang terjadi, serta jumlah penumpang/crew yang selamat dari kecelakaan tersebut. Sedangkan kinerja pelayanan dapat ditunjukkan dari kepuasan konsumen setelah pemanfaatan jasa ini. Kinerja On Time Performance (OTP) merupakan kinerja yang diukur berdasarkan kemampuan maskapai dalam memberikan jasa penerbangan yang tepat waktu atau dengan kata lain kemampuan maskapai dalam melakukan aktivitas penerbangan yang sesuai dengan waktu yang dijadwalkan. Penjadwalan ini mengacu pada tiga jenis keputusan, yaitu (1) pemeliharaan pesawat, (2) daftar jam keberangkatan, dan (3) awak pesawat (Heizer dan Render, 2011). Hal ini berarti, penjadwalan akan lebih efektif ketika ketiga keputusan tersebut dapat dikelola dengan baik. 
Tri Satya Pradnyandari, Peran Maintenance Dalam...

Pemeliharaaan pesawat mencakup seluruh aktivitas yang berkaitan dengan menjaga/memastikan peralatan sistem agar dapat bekerja (Daulay dkk, 2013). Taktik dalam pemeliharaan atau maintenance seperti menerapkan /meningkatkan aktivitas pemeliharaan preventif serta meningkatkan kemampuan/kecepatan dalam perbaikan (Heizer dalam Daulay dkk, 2013). Aktivitas ini sangat penting untuk dilakukan guna mencegah terjadinya kegagalan pada mesin khususnya dalam menjaga keselamatan para penumpang dan crew ketika aktivitas penerbangan dilakukan.

Penelitian dilakukan untuk menghasilkan bukti empiris bahwa scheduling dapat mempengaruhi kinerja maskapai penerbangan yang kemudian menghadirkan maintenance sebagai pemoderasi yang peranannya dapat memperkuat/memperlemah hubungan tersebut khususnya pada kinerja On Time Performance (OTP).

OTP menunjukkan ketepatan waktu maskapai penerbangan yang apabila melakukan penerbangan tepat waktu akan menunjukkan kinerja dalam persentase sebesar 100\% (Mahendrayani, 2016). Tolok ukur kinerja ini berupa persentase ketepatan waktu atau persentase perbandingan waktu antara scheduled time dengan actual time yang mana menjelaskan bahwa nilai OTP tinggi menunjukkan kinerja ketepatan waktu yang baik, sedangkan OTP yang rendah mengindikasikan adanya keterlambatan jadwal penerbangan (Zulaichah, 2014). Keterlambatan jadwal penerbangan atau delay dapat disebabkan oleh beberapa faktor internal maupun eksternal maskapai seperti yang diklasifikasikan oleh International Air Traffic Association (IATA) dalam Standard Delay Code: Airport Handling 
Manual 730 yang kemudian dikelompokkan oleh Direktorat Jendral Perhubungan Udara sebagai faktor penyebab keterlambatan yaitu seperti faktor teknis operasional, faktor non teknis operasional, faktor cuaca, serta faktor lain seperti kemungkinan adanya hewan yang masuk ke area runway, gangguan penerbangan di area sisi udara, turbulensi, dan lain sebagainya (Zulaichah, 2014). Faktor teknis operasional meliputi faktor penyebab yang diakibatkan oleh lingkungan eksternal contohnya seperti antrian pesawat pada saat lepas landas atau dapat diakibatkan dari lamanya pengisian bahan bakar. Faktor non teknis operasional dapat disebabkan oleh proses bagasi yang menyita waktu cukup lama, kesalahan pada saat melakukan check in, pergantian pesawat, ataupun faktor lainnya. Sedangkan faktor cuaca disebabkan oleh pembersihan salju atau cuaca yang tidak mendukung dilakukannya aktivitas penerbangan.

Satu fase penerbangan dari bandar udara asal menuju bandar udara tujuan, dimulai dari fase terbang (mulai dari persiapan terbang/preflight), taxi-out dari apron, lepas landas (take-off), terbang menanjak (climb), terbang jelajah (cruise), terbang menurun (descent), approach dan taxi-in di bandar udara tujuan (Nurhayati dan Yunitha, 2016).

Penjadwalan perusahaan penerbangan memuat keputusan strategis yang konkret terhadap berbagai macam pertimbangan seperti kapasitas jumlah armada dan rute penerbangan, ketersediaan crew, serta satu kesatuan aktivitas crew mulai dari persiapan pesawat hingga pesawat lepas landas. Penjadwalan ini berkaitan dengan flight operation yang merupakan serangkaian kegiatan yang berkaitan dengan otorisasi dan persiapan serta pelaksanaan rencana penerbangan, seperti mencakup 
Tri Satya Pradnyandari, Peran Maintenance Dalam...

flight dispatch, operation controller, dan flight following (Gifari, 2017). Secara rinci berfungsi membuat jadwal crew, tracking crew, mengatur port crew, memonitor radio navigasi, membuat flight plan, mengisi load sheet, membaca peta meteorologi, menghitung performance pesawat dalam menentukan batasan berat ketika melakukan take off maupun landing, menghitung central of gravity, dan lain sebagainya.

Aktivitas penjadwalan tidak terlepas dari kontribusi para petugas ground handling yang bersentuhan secara langsung dengan persiapan flight maupun pada post flight. Ground handling adalah suatu kegiatan maskapai yang berkaitan dengan penanganan atau pelayanan terhadap para passanger berikut bagasinya, cargo, pos, perlatan pembantu pergerakan pesawat di darat dan pesawat terbang itu sendiri selama berada di airport baik untuk departure maupun untuk arrival. Aktivitas ini memiliki ruang lingkup batas pekerjaan yaitu mulai pada fase atau tahap pre flight dan pada post flight, yaitu penanganan penumpang dan pesawat selama berada di bandara yang mana secara teknis operasional aktivitas ground handling ini dimulai pada saat pesawat taxi (berada pada parking stand), mesin sudah dimatikan, roda pesawat sudah diganjal (block on) dan pintu pesawat sudah dibuka (open the door) dan para penumpang sudah keluar dari pesawat, maka pada saat itu para staf darat sudah memiliki kewenangan untuk mengambil alih pekerjaan dari Pilot in Command (PIC) beserta cabin crew. Pekerjaan ground handling yang mengacu pada Aircraft Handling Manual (AHM 810) Annex A dalam Ground Handling Agreement, Cargo, dan Mail Handling memiliki kegiatan berdasarkan section yaitu (Susanti, 2016): Section 1: Representation 
Accomodation, Section 2 : Load Control and Communication, Section 3 : Unit Load Devisi (ULD), Section 4: Passanger \& Baggage, Section 5: Cargo \& Mail, Section 6 : Ramp, Section 7: Aircraft Servicing, Section 8: Fuel \& Oil, Section 9 : Aircraft Maintenance, Section 10 : Flight Operation \& New Administration, Section 11 : Surface Transportation, Section 12 : Catering Service, Section 13: Servicing \& Administration, Section 13: Servicing \& Administration, Section 14 : Security.

Kegiatan penjadwalan erat kaitannya dengan aktivitas penjadwalan crew oleh karena jumlah crew ataupun petugas serta fungsi dan tugas dari crew sangatlah berpengaruh terhadap kelancaran dalam persiapan flight. Disamping crewing, aktivitas penjadwalan juga memiliki kaitan dengan aktivitas bandara khususnya pada saat jam-jam sibuk karena satu fase penerbangan meliputi berbagai aktivitas pesawat dari berbagai maskapai yang beroperasi pada bandar udara tersebut serta berkaitan dengan ketersediaan fasilitas dalam mendukung operasional pesawat dari masing-masing maskapai. Satu fase penerbangan memberikan kontribusi terhadap konsumsi bahan bakar pesawat yang mana hal ini sangat penting bagi maskapai penerbangan agar dapat mengoperasikan pesawat dengan tepat waktu agar tidak menimbulkan penambahan biaya operasional penerbangan. Menjadwalkan penerbangan dengan tepat dapat menghindarkan maskapai dalam mengalami keterlambatan akibat faktor internal yang mana keterlambatan dalam kegiatan penerbangan terbagi dalam dua jenis yaitu ground delay (terjadi dimulai dari gate sebelum keberangkatan hingga taxiing menuju landasan pacu yang dapat diakibatkan oleh kepadatan lalu lintas 
Tri Satya Pradnyandari, Peran Maintenance Dalam...

penerbangan/jumlah keberangkatan melebihi kapasitas bandar udara) dan airbone delay (terjadi pada saat pesawat udara memasuki fase holding sebelum pesawat melaukan pendaratan).

Pemeliharaan (maintenance) mencakup keseluruhan aktivitas yang bertujuan untuk menjaga keseluruhan peralatan sistem agar dapat bekerja, memperpanjang umur pakai fasilitas produksi, menjamin kesiapan operasional seluruh fasilitas, menjamin keselamatan operator, mendukung kemampuan mesin untuk dapat memenuhi kebutuhan sesuai fungsinya, serta untuk mencapai tingkat biaya perawatan optimal (Heizer dan Render, 2011;Prihastono dan Prakoso, 2017). Maintenance dapat dibagi ke dalam dua macam kegiatan yaitu preventive maintenance yang meliputi pemeriksaan dan pemeliharaan berkala/rutin serta corrective maintenance yang meliputi penanganan kerusakan dan aktivitas lain setelah terjadi atau ditemukannya kerusakan. Jasa penerbangan memliki maintenance program seperti pada Tabel 2 berikut ini.

Tabel 2.

\section{Maintenance Program}

\begin{tabular}{|c|c|c|c|}
\hline Check & Lokasi & Deskripsi & Durasi \\
\hline Line & Gate & $\begin{array}{l}\text { Harian (sebelum penerbangan pertama atau saat } \\
\text { pesawat transit), kegiatan yang dilakukan meliputi } \\
\text { visual inspections seperti fluid level,tires and } \\
\text { brake, emergency equipment. }\end{array}$ & $\sim 1$ jam \\
\hline A & Gate & $\begin{array}{l}\text { Routine light maintenance dengan jenis } \\
\text { maintenance yang dilakukan meliputi engine } \\
\text { inspection. }\end{array}$ & $\sim 10 \mathrm{jam}$ \\
\hline B & Gate & $\begin{array}{l}\text { Jenis maintenance yang mirip dengan A check } \\
\text { namun dengan jenis tugas maintenance yang } \\
\text { berbeda (may occur consecutive A check) }\end{array}$ & $\begin{array}{c}\sim 10 \text { jam hingga } \sim 1 \\
\text { hari }\end{array}$ \\
\hline $\mathrm{C}$ & Hangar & $\begin{array}{l}\text { Structural inspection of airframe, opening access } \\
\text { panel meliputi routine and nonroutine } \\
\text { maintenance serta kegiatan run-in tests }\end{array}$ & $\begin{array}{c}\sim 3 \text { hari hingga } \sim 1 \\
\text { minggu }\end{array}$ \\
\hline
\end{tabular}

Bersambung.. 


\begin{tabular}{lclc}
\hline Check & Lokasi & \multicolumn{1}{c}{ Deskripsi } & Durasi \\
\hline $\mathrm{D}$ & Hangar & $\begin{array}{l}\text { Major structural inspection of the airframe after } \\
\text { paint removal, engines, landing gear, and flaps } \\
\text { removed; instruments, electronic and electrical } \\
\text { equipment removed; interior fittings removed; } \\
\text { hydraulic and pneumatic components removed. }\end{array}$ & $\sim 1$ bulan \\
\hline
\end{tabular}

Sumber: Saltoğlu et al.,2016

Hipotesis pertama yaitu scheduling berpengaruh positif terhadap kinerja maskapai penerbangan dikembangkan dengan melihat adanya korelasi secara teoritis dan penelitian terdahulu yang mana mendukung pernyataan bahwa penjadwalan yang meliputi penetapan jadwal keberangkatan, penjadwalan kegiatan, struktur tugas, crewing, serta penetapan waktu per aktivitas dapat mempengaruhi kinerja ketepatan waktu maskapai penerbangan (Billinget al., 2013; Girasyitia dan Santosa, 2015; Zulaichah, 2014; Pratama, 2015). Penelitian Girasyitia dan Santosa (2015) lebih dalam menjelaskan bahwa scheduling pada jam-jam sibuk ternyata dapat menyebabkan pada keterlambatan kedatangan pesawat. Penelitian tersebut memiliki hubungan dengan telaah literatur yang dilakukan Gifari (2017) yaitu menyatakan bahwa delay dapat terjadi akibat perencanaan aktivitas penerbangan yang kurang optimal, kebutuhan operasional yang tidak terpenuhi, terlambatnya boarding atau departure crew, kekurangan crew, adanya permintaan khusus dari crew yang bertugas, keterlambatan awak kabin, kekurangan awak kabin, ataupun adanya permintaan khusus pilot in command ketika melakukan security check. Maka dari itu, aktivitas penjadwalan ini berkaitan dengan penugasan dan aktivitas petugas, crew, maupun staf karena dianggap mampu meningkatkan produktivitas karyawan yang kemudian dapat memberikan kontribusi pada kinerja organisasi apabila dilakukan dengan tepat (Wittmer et al., 2015; Suptihati, 2014). Lebih dalam dijelaskan dalam penelitian 
Tri Satya Pradnyandari, Peran Maintenance Dalam...

Billing et al. (2013) bahwa penjadwalan kegiatan dapat menurunkan hal-hal negatif antara struktur tugas dan keterlibatan pekerjaan yang kemudian dapat meningkatkan kinerja baik dari suatu perusahaan. dengan kata lain, struktur tugas yang dibentuk dalam penjadwalan serta keterlibatan para petugas/pekerja dapat memberikan kontribusi tambatan dalam meningkatkan kinerja dari suatu perusahaan. Penelitian-penelitian serta kajian teori tersebut mendukung pengambilan hipotesis pertama yang menyatakan bahwa scheduling berpengaruh positif terhadap kinerja maskapai penerbangan.

$\mathrm{H}_{1}$ : Scheduling berpengaruh positif terhadap kinerja maskapai penerbangan.

Hipotesis kedua yaitu maintenance berperan dalam memoderasi pengaruh scheduling terhadap kinerja maskapai penerbangan dikembangkan dengan melihat korelasi secara teoritis dan penelitian terdahulu yang mana mendukung pernyataan bahwa maintenance dapat mengurangi kegagalan internal, memperkuat ataupun memperlemah scheduling, dapat menyebabkan penundaan jam keberangkatan oleh karena penanganan pesawat ketika terjadi kerusakan sehingga penjadwalan keberangkatan dapat terlaksana sesuai dengan yang dijadwalkan (Heizer dan Render, 2011; Eltoukhyet al., 2017; Gifari, 2017). Aktivitas penerbangan erat kaitannya dengan ketersediaan fasilitas dan kesiapan fasilitas untuk digunakan. Fasilitas-fasilitas ini membutuhkan kegiatan maintenance atau pemeliharaan untuk menjaga keefektifannya (Daulay dkk., 2013; Hassanain et al., 2014; Tokgöz et al., 2018). Penelitian Pratama (2015) juga mengaitkan kurangnya ketersediaan fasilitas yaitu khususnya parking stand area dapat menyebabkan keterlambatan arrival yang mana dalam hal ini penjadwalan pada jam sibuk yang didukung 
dengan adanya ketersediaan fasilitas yang siap digunakan dapat mempengaruhi kinerja dalam hal ketepatan waktu. Pernyataan terkait fasilitas tersebut didukung dengan penelitian yang telah dilakukan oleh Shanmugam dan Robert (2015) yang menjelaskan bahwa maintenance merupakan faktor krusial dalam jasa penerbangan karena 30-90\% kecelakaan dalam aktivitas penerbangan diakibatkan oleh kegagalan dalam meminimisasi human errors pada aircraft maintenance, kesesuaian maintenance untuk fasilitas bandar udara, manpower dan prosedur penggunaan peralatan secara baik dan benar. Lebih jelasnya penelitian Eltoukhy et al. (2017) menjelaskan bahwa maintenance yaitu terkait pemeliharaan operasional atau pemeliharaan secara preventive meliputi total akumulasi jam terbang, jumlah take off pesawat, dan kapasitas tenaga kerja yang melakukan pemeliharaan dapat menyebabkan penundaan jam keberangkatan penerbangan apabila tidak diperhatikan dengan baik karena faktor-faktor tersebut dapat menyebabkan waktu pemeliharaan pesawat memerlukan waktu lebih lama sebelum digunakan kembali. Berdasarkan penelitian dan kajian teori yang dipaparkan tersebut, maka hipotesis kedua yang dapat ditarik adalah maintenance berperan dalam memoderasi pengaruh scheduling terhadap kinerja maskapai penerbangan.

$\mathrm{H}_{2}$ :Maintenance berperan dalam memoderasi pengaruh scheduling terhadap kinerja maskapai penerbangan.

Penarikan kedua hipotesis tersebut dapat dijelaskan dalam model kerangka konseptual seperti yang digambarkan pada Gambar 1.

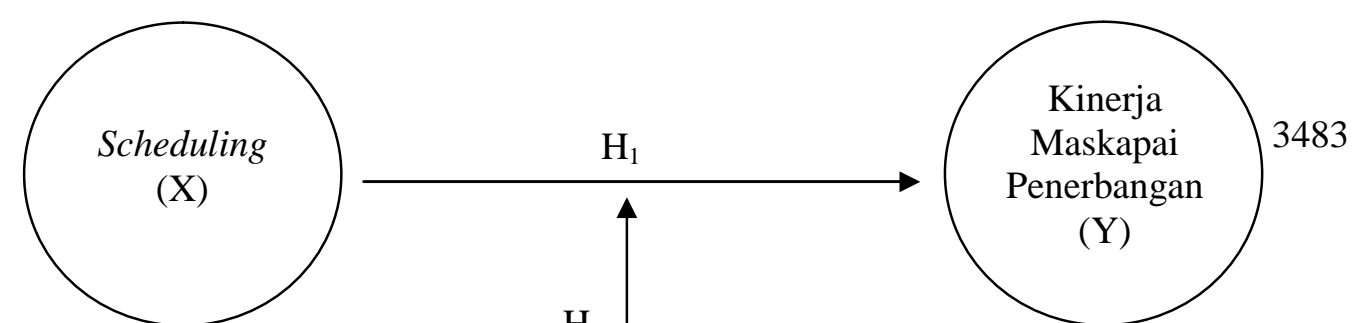


Tri Satya Pradnyandari, Peran Maintenance Dalam...

\section{Gambar 1.Model Kerangka Konseptual}

Model kerangka konseptual ini menjelaskan bahwa pengaruh penjadwalan atau scheduling terhadap kinerja maskapai penerbangan ditunjukkan oleh $\mathrm{H}_{1}$. Pengaruh ini dapat diperkuat atau diperlemah pengaruhnya oleh variabel maintenance atau pemeliharaan yan ditunjukkan oleh $\mathrm{H}_{2}$.

\section{METODE PENELITIAN}

Penelitian ini merupakan penelitian asosiatif dengan menggunakan pendekatan kuantitatif yang dilakukan untuk mengidentifikasi ada tidaknya keterkaitan kemampuan maskapai dalam maintenance (pemeliharaanperalatan/mesin yang terkait dengan aktivitas penerbangan) dengan kemampuan dalam penetapan jadwal keberangkatan yang kemudian dapat mempengaruhi kinerja dari maskapai penerbangan Garuda Indonesia di Bandara I Gusti Ngurah Rai Bali pada PT. Angkasa Pura I.

Populasi dalam penelitian ini adalah seluruh pekerja yang meliputi karyawan/staff/crew maskapai Garuda Indonesia. Kualitas data dapat sangat 
dipengaruhi dari pemilihan sampel yang tepat (Benoit et al., 2017). Sampel dalam penelitian ini anggota populasi yang dipilih sebagai sampel adalah karyawan/staff/crew yang berhubungan langsung dengan aktivitas keberangkatan pesawat. Pertimbangan dalam memilih sampel melalui teknik simple random sampling, yaitu teknik pengambilan sampel secara acak. Dalam penentuan ukuran sampel digunakan rumus Yamane seperti berikut ini (Sugiyono, 2017:149).

$$
\mathrm{n}=\frac{\mathrm{N}}{1+\mathrm{N}(\varepsilon)^{2}}
$$

Keterangan:

$\mathrm{n} \quad=$ Jumlah sampel yang diperlukan

$\mathrm{N} \quad=$ Jumlah populasi

$\varepsilon \quad=$ tingkat kesalahan sampel (sampling error)

Total populasi yaitu ground handling Garuda Indonesia yang bekerja sama dengan Gapura Group adalah sebanyak 1.200 orang. Sehingga sampel dapat dihitung dengan tingkat kesalahan sampel yang digunakan adalah 10\% seperti perhitungan berikut ini.

$$
\mathrm{n}=\frac{1.2}{1+1.2(0,1)^{2}}=\frac{1.2}{1}=92 \text { orang }
$$

Sehingga total sampel yang digunakan adalah sebanyak 92 orang stafflcrewground handling yang menangani Garuda Indonesia Airline.

Metode pengumpulan data yang dilakukan oleh peneliti adalah melalui observasi, wawancara, dan angket/kuesioner. Observasi dilakukan dengan metode non-participant observation karena pengumpulan data hanya dengan pengamatan dan tidak terlibat secara langsung. Penelitian dilakukan dengan memanfaatkan aplikasi Flightradar24 yang memuat informasi terkait jalur penerbangan, jadwal 
Tri Satya Pradnyandari, Peran Maintenance Dalam...

keberangkatan dan actual flight, rute penerbangan, serta jenis pesawat yang digunakan. Berikut disediakan gambar ilustrasi aplikasi yang telah digunakan dalam penelitian.

Wawancara dilakukan pada awal observasi dengan metode semi-structured secara formal dan informal dengan mengajukan pertanyaan secara langsung kepada pihak yang bersangkutan sehingga mendapatkan informasi mengenai perusahaan, keseluruhan aktivitas yang dilakukan crew dan staff yang bekerja langsung sebelum pesawat take off, pelaksanaan maintenance baik secara preventif ataupun korektif, flight operation, standar operasional, serta ketidakmampuan perusahaan memberikan pelayanan tepat waktu oleh karena hambatan baik secara eksternal maupun internal.

Penyebaran angket atau kuesioner dilakukan kepada responden dari crew dan staff yang bertugas, serta responden sebagai sumber data sekunder dalam penelitian. Kuesioner yang di sebar kepada responden (crew dan staff) berupa daftar pertanyaan untuk mengetahui pelaksanaan kegiatan maintenance yang telah dilakukan perusahaan, proses dan keputusan scheduling keberangkatan domestik yang diuji dengan skala likert.

Data yang diperoleh dianalisis dengan menggunakan Moderated Regression Analysis (MRA). Uji interaksi digunakan untuk mengukur peran variabel moderasi apakah memperkuat/memperlemah hubungan antara suatu variabel bebas terhadap variabel terikat (Utama, 2016:149). Moderated Regression Analysis menggunakan pendekatan analitik yang mempertahankan integritas sampel dan memberikan dasar untuk mengontrol pengaruh variabel moderator 
(Ghozali, 2016:219). Untuk menggunakan MRA dengan satu variabel predictor (X), rumus yang dapat digunakan, yaitu (Ghozali, 2016:219):

$$
Y=\alpha+\beta_{1} X_{l}+\beta_{2} Z_{l}+\beta_{3}\left(X_{i} Z_{l}\right)+\varepsilon
$$

Keterangan:

$$
\begin{aligned}
& \mathrm{Y} \quad=\text { Kinerja Maskapai Penerbangan } \\
& \alpha \quad=\text { Konstanta } \\
& \beta_{1}, \beta_{2}, \beta_{3} \quad=\text { Koefisien Regresi } \\
& \mathrm{X}_{\mathrm{i}} \quad=\text { Scheduling } \\
& \mathrm{Z}_{\mathrm{i}} \quad=\text { Maintenance } \\
& \mathrm{X}_{\mathrm{i}} \mathrm{Z}_{\mathrm{i}} \quad=\text { Interaksi antara scheduling dengan maintenance } \\
& \varepsilon \quad=\text { Standar error. }
\end{aligned}
$$

\begin{tabular}{|c|c|c|}
\hline No. & Hasil Uji & Jenis Moderasi \\
\hline 1. & $\begin{array}{c}\beta_{2} \text { non significant } \\
\beta_{3} \text { significant }\end{array}$ & Moderasi murni (pure moderator) \\
\hline 2. & $\begin{array}{l}\beta_{2} \text { significant } \\
\beta_{3} \text { significant }\end{array}$ & $\begin{array}{l}\text { Moderasi semu (quasi moderator) yaitu merupakan } \\
\text { variabel yang memoderasi hubungan antara variabel } \\
\text { independen dengan variabel dependen yang sekaligus } \\
\text { menjadi variabel independen. }\end{array}$ \\
\hline 3. & $\begin{array}{c}\beta_{2} \text { significant } \\
\beta_{3} \text { non significant }\end{array}$ & $\begin{array}{l}\text { Predikator moderasi (predicator moderation variable), } \\
\text { yaitu variabel moderasi hanya berperan sebagai } \\
\text { predikator (independen), dan bukan memoderasi dalam } \\
\text { model hubungan yang dibentuk. }\end{array}$ \\
\hline 4. & $\begin{array}{l}\beta_{2} \text { non significant } \\
\beta_{3} \text { non significant }\end{array}$ & $\begin{array}{l}\text { Moderasi potensial (homologiser moderator), yaitu } \\
\text { variabel tersebut potensial menjadi variabel moderasi. }\end{array}$ \\
\hline
\end{tabular}

Berikut ini beberapa jenis moderasi yang dilihat dari interaksi antar variabel

(Utama, 2016:150).

\section{Tabel 3.}

Jenis Peran Moderasi

Sumber: Suyana Utama, 2016

Koefisien moderasi dapat menjelaskan bagaimana peranan $\mathrm{Z}$ kepada pengaruh variabel bebas $(\mathrm{X})$ terhadap variabel terikat $(\mathrm{Y})$ dengan jenisperanan dapat memperlemah atau memperkuat. Berikut ini adalah penjelasan dengan melihat koefisien $\beta_{1}$ dan $\beta_{3}$ (Utama, 2016:150).Jika $\beta_{1}$ positif, signifikan atau tidak, dan $\beta_{3}$ positif signifikan, maka $\mathrm{Z}$ sebagai variabel moderasi yang memperkuat variabel $X$ terhadap $Y$, jika $\beta_{1}$ negatif, signifikan atau tidak, dan $\beta_{3}$ negatif signifikan, maka $\mathrm{Z}$ sebagai variabel moderasi yang memperkuat pengaruh 
Tri Satya Pradnyandari, Peran Maintenance Dalam...

X terhadap Y, Jika $\beta_{1}$ positif, signifikan atau tidak, dan $\beta_{3}$ negatif signifikan, maka $\mathrm{Z}$ sebagai variabel moderasi yang memperlemah pengaruh $\mathrm{X}$ terhadap $\mathrm{Y}$, jika $\beta_{1}$ negatif, signifikan atau tidak, dan $\beta_{3}$ positif signifikan, maka $\mathrm{Z}$ sebagai variabel moderasi yang memperlemah pengaruh $\mathrm{X}$ terhadap $\mathrm{Y}$.

\section{HASIL PENELITIAN DAN PEMBAHASAN}

Uji validitas dilakukan untuk memeriksa pengukuran indikator penelitian sudah tepat di dalam instrumen penelitian yang berupa kuesioner. Indikator dianggap valid jika nilai $r_{\text {hitung }}$ lebih besar dari $r_{\text {tabel }}(r>0,207)$. Hasil penelitian tersedia pada Tabel 4.

Tabel 4.

Hasil Uji Validitas

\begin{tabular}{|c|c|c|c|c|}
\hline No. & Variabel & Indikator & $\begin{array}{l}\text { Koef. } \\
\text { Korelasi }\end{array}$ & Ket. \\
\hline \multirow[t]{14}{*}{1.} & \multirow[t]{14}{*}{ Kinerja (Y) } & $\left(\mathrm{Y}_{1.1}\right)$ Penanganan penumpang dan bagasi & 0,587 & Valid \\
\hline & & $\left(\mathrm{Y}_{1.2}\right)$ Penanganan penumpang dan bagasi & 0,440 & Valid \\
\hline & & $\left(\mathrm{Y}_{1.3}\right)$ Penanganan aircraft andramp handling & 0,509 & Valid \\
\hline & & $\left(\mathrm{Y}_{1.4}\right)$ Penanganan technical and aircraft equipment & 0,320 & Valid \\
\hline & & $\left(\mathrm{Y}_{1.5}\right)$ Penanganan flight operation & 0,669 & Valid \\
\hline & & $\left(\mathrm{Y}_{1.6}\right)$ Penanganan dan penjadwalan crew & 0,706 & Valid \\
\hline & & $\left(\mathrm{Y}_{1.7}\right)$ Air Traffic Flow Management Restrictions & 0,543 & Valid \\
\hline & & $\left(\mathrm{Y}_{1.8}\right)$ Faktor keterlambatan akibat penanganan bagasi & 0,333 & Valid \\
\hline & & $\begin{array}{l}\left(\mathrm{Y}_{1.9}\right) \text { Faktor keterlambatan akibat operasional } \\
\text { penerbangan }\end{array}$ & 0,435 & Valid \\
\hline & & $\left(\mathrm{Y}_{1.10}\right)$ Faktor keterlambatan akibat ground handling & 0,448 & Valid \\
\hline & & $\left(\mathrm{Y}_{1.11}\right)$ Faktor keterlambatan akibat aktivitas preflight & 0,276 & Valid \\
\hline & & $\begin{array}{l}\left(\mathrm{Y}_{1.12}\right) \text { Faktor keterlambatan akibat teknis } \\
\text { penerbangan }\end{array}$ & 0,504 & Valid \\
\hline & & $\begin{array}{l}\left(\mathrm{Y}_{1.13}\right) \text { Faktor keterlambatan akibat operasi } \\
\text { penerbangan }\end{array}$ & 0,564 & Valid \\
\hline & & $\begin{array}{l}\left(\mathrm{Y}_{1.14}\right) \text { Faktor keterlambatan akibat } \\
\text { penjadwalan/pergantian } \text { crew }\end{array}$ & 0,422 & Valid \\
\hline \multirow[t]{7}{*}{2.} & Scheduling & $\left(\mathrm{X}_{1.1}\right)$ Pilot in command (PIC) & 0,672 & Valid \\
\hline & $(\mathrm{X})$ & $\left(\mathrm{X}_{1.2}\right)$ Penjadwalan flight officer & 0,678 & Valid \\
\hline & & $\left(\mathrm{X}_{1.3}\right)$ Ketepatan flight attendant & 0,591 & Valid \\
\hline & & $\left(\mathrm{X}_{1.4}\right)$ Pemahaman crew & 0,585 & Valid \\
\hline & & $\left(\mathrm{X}_{1.5}\right)$ Briefing & 0,541 & Valid \\
\hline & & $\left(\mathrm{X}_{1.6}\right)$ Ketepatan waktu kerja crew & 0,470 & Valid \\
\hline & & $\left(\mathrm{X}_{1.7}\right)$ Penjadwalan penerbangan & 0,781 & Valid \\
\hline \multirow[t]{3}{*}{3.} & Maintenance & $\left(Z_{1.1}\right)$ Pembersihan & 0,725 & Valid \\
\hline & $(\mathrm{Z})$ & $\left(\mathrm{Z}_{1.2}\right)$ Pengecekan & 0,672 & Valid \\
\hline & & $\left(\mathrm{Z}_{1.3}\right)$ Penyetelan & 0,694 & Valid \\
\hline
\end{tabular}




\begin{tabular}{cccc}
\hline No. Variabel & \multicolumn{1}{c}{ Indikator } & $\begin{array}{c}\text { Koef. } \\
\text { Korelasi }\end{array}$ & Ket. \\
\hline & $\left(\mathrm{Z}_{1.4}\right)$ Pengisian bahan bakar & 0,478 & Valid \\
& $\left(\mathrm{Z}_{1.5}\right)$ Durasi aktivitas maintenance & 0,244 & Valid \\
& $\left(\mathrm{Z}_{1.6}\right)$ Kemampuan menemukan penyebab kerusakan & 0,660 & Valid \\
& $\left(\mathrm{Z}_{1.7}\right)$ Kemampuan perbaikan & 0,577 & Valid \\
& $\left(\mathrm{Z}_{1.8}\right)$ Overhaul & 0,616 & Valid \\
$\left(\mathrm{Z}_{1.9}\right)$ Kemampuan perbaikan & 0,654 & Valid \\
\hline Sumber: Data Diolah 2018 & &
\end{tabular}

Tabel 4 menunjukkan hasil perhitungan untuk variabel kinerja adalah valid (keseluruhan indikator valid), variabel scheduling adalah valid (keseluruhan indikator valid), dan variabel maintenance adalah valid (keseluruhan indikator valid).

Uji reliabilitas dilakukan untuk mengetahui konsistensi alat ukur dalam penggunaannya. Instrumen reliabel apabila digunakan beberapa kali untuk mengukur obyek yang sama namun tetap menghasilkan data yang sama. Variabel reliabel jika Cronbach's Alpha memperoleh nilai yang lebih besar dari 0,6. Penjelasan terdapat pada Tabel 5.

Tabel 5.

Hasil Uji Reliabilitas

\begin{tabular}{clcc}
\hline No. & \multicolumn{1}{c}{ Variabel } & Cronbech'sAlpha & Keterangan \\
\hline 1. & Kinerja $(\mathrm{Y})$ & 0,748 & Reliabel \\
2. & Scheduling $(\mathrm{X})$ & 0,729 & Reliabel \\
3. & Maintenance $(\mathrm{Z})$ & 0,768 & Reliabel \\
\hline
\end{tabular}

Sumber:Data Diolah, 2018

Pengaruh schedulingdan peranan maintenance dapat dilihat dari hasil scoring kuesioner yang kemudian diolah dengan menggunakan aplikasi SPSS 24.

Berdasarkan hasil yang diperoleh dari rekapitulasi hasil MRA, hasil analisis koefisien regresi pada Tabel 6 adalah sebagai berikut.

$$
Y=-45,251+3,649 X_{i}+1,646 Z_{i}-0,061\left(X_{i} Z_{i}\right)
$$


Tabel 6.

\section{Rekapitulasi Hasil MRA}

\begin{tabular}{|c|c|c|c|c|c|c|}
\hline \multirow[t]{2}{*}{ Model } & & \multicolumn{2}{|c|}{$\begin{array}{l}\text { Unstandardized } \\
\text { Coefficients }\end{array}$} & \multirow{2}{*}{$\begin{array}{l}\text { Standardized } \\
\text { Coefficients } \\
\text { Beta }\end{array}$} & \multirow[t]{2}{*}{$\mathrm{t}$} & \multirow[t]{2}{*}{ Sig. } \\
\hline & & B & Std. Error & & & \\
\hline \multirow[t]{7}{*}{1} & (Constant) & $-45,251$ & 19,906 & & $-2,273$ & 0,025 \\
\hline & Scheduling (X) & 3,649 & 0,720 & 2,320 & 5,070 & 0,000 \\
\hline & Maintenance $(\mathrm{Z})$ & 1,646 & 0,527 & 1,363 & 3,121 & 0,002 \\
\hline & $\mathrm{X} * \mathrm{Z}$ & $-0,061$ & 0,019 & $-2,463$ & $-3,225$ & 0,002 \\
\hline & Adjusted $\mathrm{R}^{2}$ & 0,733 & & & & \\
\hline & $\mathrm{F}_{\text {hitung }}$ & 84,170 & & & & \\
\hline & Sig. F & 0,000 & & & & \\
\hline
\end{tabular}

Sumber:Data Diolah, 2018

Berdasarkan persamaan di atas, dapat dijelaskan bahwa nilai konstanta sebesar 45,251 menunjukkan bahwa bila scheduling dan maintenance tidak dilakukan, maka kinerja akan menurun, nilai koefisien regresi $\mathrm{X}$ sebesar $\beta_{1}$ sebesar 3,649 menunjukkan bahwa bila scheduling membaik, maka kinerja akan meningkat dengan asumsi variabel lainnya konstan, nilai koefisien regresi $\mathrm{Z}$ sebesar $\beta_{2}$ sebesar 1,646 menunjukkan bahwa bila maintenance membaik, maka kinerja meningkat dengan asumsi variabel lainnya konstan, nilai koefisien regresi X.Z sebesar $\beta_{3}$ sebesar $-0,061$ menunjukkan bahwa bila interaksi antara scheduling dengan maintenance membaik, maka kinerja akan menurun dengan asumsi variabel lainnya konstan, Uji kelayakan model (Uji F) merupakan pengujian untuk mengetahui apakah model digunakan dapat dikatakan layak atau tidak untuk digunakan sebagai alat analisis dalam menguji pengaruh pada variabel dependennya. Tabel 10 menunjukkan nilai 84,170 dan nilai $p$-value (Sig. F) yakni 0,000 yaitu lebih kecil dari nilai $\alpha=0,05$ sehingga model ini dapat dikatakan fit atau signifikan, koefisien determinasi $\left(\mathrm{R}^{2}\right)$ bernilai 0,733 memiliki arti bahwa $73,3 \%$ variasi kinerja dapat dijelaskan oleh variasi variabel independen scheduling, maintenance, dan moderasi (perkalian variabel scheduling dengan 
maintenance). Sedangkan sisanya 26,7\% dijelaskan oleh faktor-faktor lain di luar model.

Scheduling maupun maintenance merupakan variabel yang apabila tidak dilakukan ternyata dapat menurunkan kinerja maskapai penerbangan. Interpretasi lainnya menjelaskan bahwa scheduling memiliki hubungan yang positif dengan kinerja yang mana apabila scheduling membaik maka kinerja maskapai pun akan meningkat khususnya pada kinerja ketepatan waktu/on time performance. Hubungan positif ini juga dapat ditunjukkan dari variabel maintenance dengan kinerja yang mana bila maintenance membaik maka akan ada peningkatan kinerja dengan asumsi bahwa variabel lainnya konstan. Namun hasil negatif ditemukan pada interaksi ketika maintenance dihadirkan sebagai variabel pemoderasi. Maintenance memberikan peranan yang dapat melemahkan pengaruh scheduling terhadap kinerja. Penelitian ini juga menemukan bahwa variabel pemoderasi yaitu maintenance tergolong sebagai variabel moderasi semu (quasi moderator) yaitu merupakan variabel yang memoderasi hubungan antara variabel independen yang sekaligus dapat menjadi variabel independen (deskripsi ini diperoleh dengan melihat nilai $\beta_{2}$ dan $\beta_{3}$ yang signifikan yaitu $\left.\beta_{2}=\beta_{3}=0,02<\alpha=0,05\right)$.

Secara teoritis, scheduling merupakan suatu perencanaan kapasitas yang mencakup ketersediaan seluruh sumber daya fasilitas dan peralatan, yang mana pada jasa penerbangan, keputusan penjadwalan berkaitan dengan pembebanan kerja atau pembatasan waktu kerja, rangkaian aktivitas, serta ketersediaan crew, sehingga dalam proses penjadwalan, aspek-aspek kegiatan, waktu, dan crew merupakan aspek penting yang perencanaannya melihat kapasitas dan 
Tri Satya Pradnyandari, Peran Maintenance Dalam...

kemampuan sumber daya tersebut. Kinerja maskapai penerbangan khususnya terkait On Time Performance (OTP), memiliki tolok ukur berupa persentase ketepatan waktu keberangkatan udara dari total jumlah jadwal penerbangan yang dimiliki. Maka secara teoritis, penjadwalan mempengaruhi OTP maskapai penerbangan.

Penelitian ini menemukan hasil koefisien regresi dari variabel scheduling terhadap kinerja sebesar 3,649, artinya scheduling berpengaruh positif terhadap kinerja dengan tingkat signifikansi sebesar 0,000 lebih kecil dari $\alpha=0,05$. Hasil ini menerima hipotesis $\mathrm{H}_{1}$ yakni scheduling berpengaruh terhadap kinerja maskapai penerbangan. Pengaruh yang positif ditunjukkan dari tanda positif pada koefisien regresi variabel scheduling.Hasil penelitian ini sejalan dengan penelitian Wu (2005) yang menghasilkan penemuan OTP dapat terjadi ketika perencanaan penjadwalan dilakukan dengan andal/fleksibel oleh karena analisa skenario menunjukkan adanya kerentanan pada jadwal penerbangan. Selain itu, scheduled flight juga dianggap mampu meningkatkan dan menurunkan biaya tambahan untuk mengantisipasi ketidakmampuan maskapai dalam mencapai scheduled time arrival sehingga dalam penelitian ditemukan bahwa scheduling mempengaruhi OTP karena penjadwalan yang tidak optimal akan menimbulkan biaya penanganan delay yang disesuaikan dengan bentuk kategori kelas jasa yang dibeli oleh penumpang (Deshpande and Arikan, 2012). Penelitian lainnya juga menemukan bahwa jadwal penerbangan yang direpresentasikan dalam bentuk Direct Acylic Graph (DAG) dengan peristiwa jadwal yang dilambangkan dengan node (meliputi aktivitas penerbangan pesawat, flight wheels-off, flight wheelson, 
kedatangan pesawat, dan lain sebagainya) serta aktivitas berbeda yang membutuhkan kejadian dilambangkan dengan arcs (meliputi aktivitas taxiingoutflying, taxiing-in, resource connection, dan sebagainya) memiliki korelasi dengan alasan terjadinya delay (Abdelghany et al., 2004). Hasil ini juga mendukung penelitian-penelitian lainnya yang menyatakan bahwa scheduling dapat mempengaruhi kinerja (Suprihati, 2014; Billing et al., 2013; Girasyitia dan Santosa, 2015; Tannady dkk, 2017). Sehingga hasil ini memberikan kesimpulan yang sama dengan Gifari (2017) bahwa flight operation yang mana merupakan salah satu indikator dalam scheduling dapat mempengaruhi on time performance dan merupakan faktor yang memiliki daya dongkrak lebih besar dibandingkan variabel lainnya dalam model penelitiannya seperti faktor teknik.

Berdasarkan hasil olahan data pada Tabel 6, diperoleh nilai t hitung sebesar -3,225 memiliki nilai yang lebih besar dari t tabel dengan df=90 sebesar 1,987, nilai signifikansi uji t yakni p-value sebesar 0,002 lebih kecil dari $\alpha=0,05$, serta nilai koefisien regresi sebesar -0,061 memiliki arti bahwa hipotesis kedua atau $\mathrm{H}_{2}$ penelitian dapat diterima dan maintenance dapat memoderasi hubungan antara scheduling dengan kinerja maskapai penerbangan dengan bentuk pengaruh yang dapat melemahkan hubungan antara variabel tersebut.

Maintenance mencakup semua aktivitas yang berkaitan dengan menjaga semua peralatan sistem agar dapat bekerja sehingga variabel ini secara teoritis bertujuan untuk menjamin kesiapan operasional seluruh fasilitas serta mendukung kemampuan mesin dalam memenuhi keselamatan dan kebutuhan aktivitas 
Tri Satya Pradnyandari, Peran Maintenance Dalam...

penerbangan. Dengan demikian, variabel ini dihadirkan sebagai sebuah variabel yang memoderasi pengaruh scheduling terhadap kinerja maskapai penerbangan.

Hasil penelitian ini sejalan dengan penelitian Anggoro (2014) yang menemukan bahwa penerapan maintenance dengan basis Oracle Alert dapat meningkatkan kedatangan forklift sesuai jadwal atau secara otomatis dapat menurunkan unplanned downtime dan dampak negatif dari akibat kerusakan saat penggunaan. Penambahan aktivitas atau durasi dalam aktivitas maintenance yang tidak dijadwalkan, dapat menyebabkan gangguan dalam suatu proses aktivitas produksi suatu produk sehingga aktivitas yang semestinya dapat dilakukan dengan tepat waktu menjadi tidak efisien dan efektif, sebaliknya maintenance terencana dapat membantu meminimasi waktu downtime dan meningkatkan reliability serta mengurangi tingkat breakdown pada mesin (Anggoro, 2014; Prihastono dan Prakoso, 2017). Meskipun penelitian menemukan hasil bahwa maintenance dapat memperlemah pengaruh scheduling terhadap kinerja maskapai, bukan berarti aktivitas maintenance dapat diturunkan durasi per aktivitas ataupun aktivitasnya untuk menciptakan ketepatan waktu yang lebih optimal, karena preventive maupun corrective maintenance dapat berpengaruh signifikan terhadap Mean Time Between Failures atau waktu kegagalan rata-rata antara kegagalan dari suatu mesin yang dihitung dari mesin pertama kali diperbaiki sampai terjadinya kegagalan lagi (Daulay dkk., 2013; Eltoukhy et al., 2017; Yuliana, 2015). Kegagalan mesin dalam bekerja dapat memberikan dampak negatif yang sangat buruk dalam industri penerbangan karena hal ini menyangkut keselamatan penumpang dan crew. Pada penelitian ini, hasil melemahkan disebabkan oleh 
batasan penelitian pada variabel kinerja yang mana batasan tersebut mendefinisikan kinerja maskapai dalam bentuk ketepatan waktu. Penambahan aktivitas maintenance dapat menyebabkan penambahan waktu dalam persiapan flight. Penambahan waktu persiapan tersebut dapat mengurangi ketepatan waktu maskapai meskipun sebelumnya jadwal penerbangan sudah ditentukan. Penambahan waktu maintenance ini dapat terjadi akibat kurangnya kemampuan petugas dalam menemukan permasalahan pada mesin atau pesawat ataupun pada bagian kerusakan lainnya. Dapat juga diakibatkan oleh human error karena dalam pengerjaan maintenance diperlukan tenaga manusia yang tenaga dan aktivitasnya tidak dapat dipaksa ketepatannya sesuai durasi yang telah dijadwalkan.

Hasil dari penelitian ini dapat memberikan wawasan dalam pemahaman terkait jasa penerbangan. Jasa penerbangan sesungguhnya memiliki tiga kunci utama dalam penilaian kinerja yaitu (1) keselamatan, (2) On Time Performance (OTP), dan (3) pelayanan kepada konsumen. Penelitian ini memberikan pemahaman secara mengkhusus terkait kinerja ketepatan waktu/OTP dengan pengaruh variabel scheduling secara positif. Disamping itu, selain menunjukkan adanya pengaruh penjadwalan terhadap kinerja, penelitian ini juga menemukan peran maintenance sebagai variabel pemoderasi yang ternyata mampu memperlemah pengaruh antara scheduling terhadap kinerja maskapai penerbangan. Penelitian ini memiliki batasan yaitu variabel memiliki beberapa indikator yang tentunya belum dapat menjelaskan keseluruhan variabel-variabel dalam penelitian, sehingga civitas akademika yang tertarik untuk mengangkat dan meneruskan penelitian ini dapat menghadirkan indikator lain dari masing-masing 
Tri Satya Pradnyandari, Peran Maintenance Dalam...

variabel yang sekiranya dapat menjelaskan variabel tersebut dan pengaruhnya terhadap variabel lainnya.

Penelitian ini akan memberikan kontribusi bagi pihak manajemen Garuda Indonesia Airline dalam bentuk dasar pemikiran dalam pengambilan keputusan strategis terkait penjadwalan sehingga kinerja ketepatan waktu dapat lebih ditingkatkan. Meskipun maintenance memberikan hasil yang dapat melemahkan pengaruh scheduling terhadap kinerja namun maskapai harus tetap mengoptimalkan dan menyesuaikan proses maintenance sesuai dengan prosedur yang distandarkan. Agar maintenance tidak mengurangi OTP maskapai, maka maskapai dapat menjadwalkan aktivitas maintenance secara optimal karena maintenance sangat penting untuk menjaga keselamatan operator, crew, dan penumpang, memperpanjang umur pakai fasilitas, serta menjaga keefektifan fasilitas ketika dioperasikan.

\section{SIMPULAN DAN SARAN}

Berdasarkan hasil analisis dan pembahasan, didapatkan simpulan scheduling dapat berpengaruh positif signifikan terhadap kinerja maskapai penerbangan. Sehingga dalam meningkatkan kinerja maskapai penerbangan khususnya dalam On Time Performance (OTP), penjadwalan crew dan durasi per aktivitas harus direncanakan dengan tepat, memberlakukan sistem briefing untuk memberikan pemahaman kepada seluruh crew terkait aktivitas penerbangan yang akan dilakukan, serta sikap disiplin dan komitmen baik pilot in command dan flight officer dalam menciptakan penerbangan yang tepat waktu.Maintenance mampu berperan sebagai variabel pemoderasi pengaruh scheduling terhadap kinerja 
maskapai penerbangan dengan peranan yang memperlemah pengaruh antar variabel tersebut. Peran memperlemah terjadi akibat aktivitas maintenance yang belum dilakukan dengan tepat sesuai dengan durasi yang distandarkan akibat human error, kurangnya kemampuan crew dalam menemukan permasalahan dengan cepat, serta faktor lainnya yang menyebabkan penambahan waktu dalam pelaksanaan aktivitas maintenance. Penambahan waktu akan berakibat pada ketidaktepatan jadwal keberangkatan sesuai dengan yang dijadwalkan sehingga kinerja ketepatan waktu akan menurun. Hasil maintenance yang melemahkan pengaruh scheduling terhadap kinerja maskapai penerbangan diperoleh karena perhitungan atau standar kinerja yang digunakan adalah waktu sehingga penambahan aktivitas maintenance dapat berdampak pada penambahan waktu persiapan flight sehingga menurunkan kinerja ketepatan waktu maskapai.

Controlling/evaluasi terkait penyebab keterlambatan penerbangan harus diperhatikan lebih lanjut yaitu melalui aktivitas controlling/evaluasi terhadap faktor-faktor yang dapat menyebabkan pembatalan ataupun penundaan penerbangan (seperti faktor teknis operasional, non teknis operasional, cuaca, dan faktor lainnya) yang dapat menyebabkan penurunan pada On Time Performance (OTP). Perusahaan juga harus melakukan pelatihan-pelatihan kepada crew yang menangani aktivitas maintenance sehingga dapat mengurangi terjadinya human error, meningkatkan kemampuan crew dalam menemukan masalah pada pesawat dengan cepat, serta meningkatkan komitmen dan kedisiplinan crew agar penerbangan yang tepat waktu dapat diraih secara berkelanjutan. 
Tri Satya Pradnyandari, Peran Maintenance Dalam...

Peneliti selanjutnya dapat menambahkan dimensi lain pada variabel scheduling seperti crewing yang mencakup pengaruh kapasitas/ketersediaan crew, kapasitas/ketersedian parking stand area di Bandar Udara I Gusti Ngurah Rai, penjadwalan pada saat jam sibuk, ataupun dimensi lainnya yang dapat mempengaruhi kinerja ketepatan waktu. Peneliti selanjutnya juga dapat melakukan penelitian dengan menghadirkan variabel-variabel lainnya yang tidak hanya dapat mempengaruhi kinerja ketepatan waktu, melainkan dapat pula mempengaruhi kinerja keselamatan dan kinerja pelayanan kepada konsumen.

\section{REFERENSI}

Abdelghany, Khaled F., Sharmila, S. Shah., Sidhartha, Raina., \& Abdelghany, Ahmed F. (2004). A Model for Projecting Flight Delays During Irregular Operation Conditions. ELSEVIER Journal of Air Transport Management 10 (2004) pp. 385-394 https://doi.org/10.1016/j.jairtraman.2004.06.008.

Anggoro, Susetyo. (2014). Pengembangan Sistem Manajemen Perawatan Forklift dengan Pendekatan Reliability Centered Maintenance (RCM) Berbasis Oracle Alert System (Studi pada PT Gajah Tunggal Tbk Tanggerang). Jurnal $O E$ Vol. VI No.2 238-252. Diunduh dari situs https://publikasi.mercubuana.ac.id/index.php/oe/article/view/514/454.

Badan Pusat Statistik. (2018) Jumlah Penumpang Penerbangan Domestik di Bandar Utama Indonesia Periode 2013-2017.www.bps.go.id.

Benoit, Sabine., Scherschel, Katrin., Ates, Zelal., Nasr, Linda., \& Kandampully, Jay. (2017). Showcasing the Diversity of Service Research. Emerald Group Publishing,Journal of Service Management Emerald Publishing Limited 1757-5818 https://doi.org/10.1108/JOSM-05-2017-0102.

Billing, Tejinder K., Bhagat Rabi S., \& Babakus, Emin. (2013). Task Structure and Work Outcomes (Exploring the Moderating Role of Emphasis on Scheduling). Emerald Group Publishing Limited Management Research Review Vol. $36 \quad$ No. 2 (2040-8269) pp. 136-152 https://doi.org/10.1108/0140917. 
Daulay, Iwan Nauli., Nurutami, Sri Sitiani., \& Daniel, Dian Denisha. (2013). Analisis Maintenance Reliability terhadap Mean Time Between Failures (MTBF) Facilities pada Industri Pulp \& Paper. Jurnal Ekonomi Vol. 21 No. 4 Desember (2013) 1-18. Diunduh dari situs https://ejournal.unri.ac.id/index.pphp/JE/article/view/2044.

Deshpande, Vinayak., \& Arikan, Mazhar. (2012). The Impact of Airline Flight Schedules on Flight Delays. Manufacturing \& Service Operations Management Vol. 14 No. 3 Summer 2012 pp.423-440 https://dx.doi.org/10.1287/msom.1120.0379 INFORMS.

Eltoukhy, Abdelrahman E.E., Chan, Felix T.S., \& Chung, S.H. (2017). Airline Schedule Planning: a Review and Future Directions. Emerald Group Publishing Limited, Industrial Management \& Data Systems Vol. 117 Issues 6 (IMDS-09-2016-0358) https://doi.org/10.1108/IMDS-09-2016-0358.

Gifari, Mahardhito. (2017). Hubungan Delay Karena Penanganan Flight Operation dan Teknik dengan On Time Performance pada Maskapai Penerbangan NAM Air di Bandar Soekarno-Hatta. Skripsi. Sekolah Tinggi Manajemen Transportasi Trisakti. Jakarta.

Ghozali, Imam. (2016). Aplikasi Analisis Multivariate dengan Program IBM SPSS 23. Semarang: Badan Penerbit Universitas Diponegoro.

Girasyitia, Ganayu., \& Santosa, Wimpy. (2015). Evaluasi On Time PerformancePesawat Udara di Bandar Udara Husein Sastranegara Menggunakan Aplikasi Flightradar24. Jurnal Transportasi Vol. 15 No.2 hal. 143-150. https://journal.unpar.ac.id/index.php/journaltransportasi/article/view/1732.

Hassanain, Mohammad A., Sadi, Assaf, Abdul-Mohsen, Al-Hammad, \& Ahmed Al-Nehmi. (2015). A Multi-Criteria Decision Making Model for Outsourcing Maintenance Service. Emerald Group Publishing, Facilities Vol. 33 No. 3/4 pp. 229-244 https://doi.org/10.1108/F-01-2013-0003.

Heizer, Jay., \& Render, Barry. (2011). Manajemen Operasi Buku 2 Edisi 9. Jakarta: Salemba Empat.

, Jay., \& Render, Barry. (2015). Manajemen Operasi: Manajemen Keberlangsungan dan Rantai Pasokan, Edisi Kesebelas. Jakarta: Salemba Empat.

Mahendrayani, Ni Wayan Ita. (2016). Pengaruh Kualitas Layanan terhadap Kepuasan Pelanggan dengan Kepercayaan sebagai Variabel Intervening (Studi pada Pelanggan Lion Air DiBandara Juanda Surabaya). Jurnal Ilmu Manajemen Volume 4 Nomor 3. Diunduh dari situs Jurnal Imu Manajemen http://jurnalmahasiswa.unesa.ac.id/index.php/jim/article/view/17277. 
Nurhayati, Yati., \& Yunitha, Ardiani Nur. (2016). Peran Jasa Ground Handling Terhadap Pelayanan Perusahaan Air Freight di Bali dalam Menghadapi Kompetisi Global. Warta Ardhia Volume 42 No. 1 Maret 2016 hal.45-46. https://wartaardhia.com/index.php/wartaardhia.

Pratama, Yunanda Adrika. (2015). Pengaruh Jumlah Keterbatasan Parking Stand Area Terhadap Keterlambatan Kedatangan Pesawat Komersial di Bandar Udara Husein Sastranegara Bandung. Jurnal Ground Handling Dirgantara Vol. 2 No. 2 57-75. Diunduh melalui situs Jurnal Ground Handling http://jurnal.sttkd.ac.id/index.php/JGH/article/download/124/97.

Prihastono, Endro., \& Prakoso, Brian. (2017). Perawatan Preventif untuk Mempertahankan Utilitas Performance pada Mesin Cooling Tower di CV. Arhu Tapselindo Bandung. Dinamika Teknik Vol. X No. 2 hal. 17-27. https://www.unisbank.ac.id/ojs/index.php/ft1/article/view/5581.

Saltoğlu, Remzi., Humaira, Nazmia., \& nalhan, Gökhan. (2016). Aircraft Scheduled Airframe Maintenance and Downtime Integrated Cost Model. Hindawi Publishing Corporation Advances in Operation Research Volume 201612 pages Article ID 2576825 dx.doi.org/10.1155/2016/2576825.

Shanmugam, A. \& Robert, T. Paul. (2015). Human Factors Engineering in Aircraft Maintenance: a Review. Emerald Group Publishing Limited Journal of Quality in Maintenance Engineering Vol. 21 No.4 1355-2511 pp. 478-505. https://doi.org/10.1108/JQME-05-2013-0030.

Sugiyono. (2017). Metode Penelitian Bisnis. Bandung: Alfabeta.

Suprihati. (2014). Analisis Faktor-Faktor yang Mempengaruhi Kinerja Karyawan Perusahaan Sari Jati di Sragen. Jurnal Paradigma Vol. 12 No. 01 hal. 93112. Diunduh melalui https://media.neliti.com/media/publications/115677ID-analisis-faktor-faktor-yang-mempengaruhi.pdf.

Susanti. (2016). Kajian Human Factor SDM Ground Handling di Bandar Udara Adi Sucipto Yogyakarta. Warta Ardhia Volume 42 No. 1 Maret 2016 hal.29-42. http://dx.doi.org/10.25104/wa.v42i1.290.29-42.

Sutandi, A. Caroline. (2015). Pentingnya Transportasi Umum untuk Kepentingan Publik. Jurnal Administrasi Publik Vol. 12 No. 1 (April 2015) 19-34. Diunduh melalui situs journal.unpar.ac.id/index.php/JAP/article/view/1498.

Suprihati. (2014). Analisis Faktor-Faktor yang Mempengaruhi Kinerja Karyawan Perusahaan Sari Jati di Sragen. Jurnal Paradigma Vol. 12 No. 01 hal. 93112. Diunduh melalui https://media.neliti.com/media/publications/115677ID-analisis-faktor-faktor-yang-mempengaruhi.pdf. 
Tokgöz., Serol Bulkan, Selim Zaim, Dursun Delen, N. Gökhan Torlak. (2018). Modeling Airline MRO Operations Using a Systems Dynamics Approach: a Case Study of Turkish Airlines. Emerald Publishing Limited, Journal of Quality in Maintenance Engineering Vol. 24 Issue 3 pp. 1-48. Diunduh melalui situs https://doi.org/10.1108/JQME-05-2017-0037.

Utama, Made Suyana. (2016). Buku Ajar Aplikasi Analisis Kuantitatif untuk Ekonomi dan Bisnis. Denpasar: CV. Sastra Utama.

Wittmer, Jenell L.S., Shepard, Agnieszka K., \& Martin, James E. (2015). Schedule Preferences, Congruence, and Employee Outcomes in Unionized Shift Workers. Emerald Publishing Limited, American Journal of Business Vol.30 No. 1 pp.92-110. https://doi.org/10.1108/AJB-01-2014-0001.

$\mathrm{Wu}$, Cheng-Lung. (2005). Inherent Delays and Operational Reliability of Airline Schedules. ELSEVIER Journal of Air Transport Management (2005)pp.273282 doi.org/10.1016/j.jairtraman.2005.01.005.

Yuliana, Dina. (2017). Pengaruh Fasilitas, Layanan dan Informasi Aksesibilitas terhadap Tingkat Kepuasan Penumpang di Bandara Husein Sastranegara Bandung. Jurnal Warta Ardhia Vol. 43 No. 1 Juni 2017 hal 27-42. Diakses melalui http://dx.doi.org/10.25104/wa.v43i1.235.27-42.

Zulaichah. 2014. Pengaruh Fasilitas Bandar Udara Terhadap Kinerja Ketepatan Waktu Maskapai Penerbangan. Jurnal Warta Ardhia Vol. 40 No. 4 Desember 2014 hal.223-234. http://dx.doi.org/10.25104/wa.v40i4.219.223234. 